\title{
Aplikasi POC POMI dan Kompos Tricho Jagung Terhadap Pertumbuhan Kailan (Brassica oleraceae.L)
}

\section{Application of POC POMI and Tricho Corn Compost On The Growth of Kailan (Brassica Oleraceae. L)}

\author{
Wahyudi Narullova \\ Balai Pelatihan Pertanian Jambi, Jambi, Indonesia \\ email: wahyudinarullova@gmail.com
}

\begin{tabular}{ll}
\hline I N F O A R T I K E L & \multicolumn{1}{c}{ A B S T R A K } \\
\hline Sejarah artikel: & Penelitian ini bertujuan untuk melihat dampak konsentrasi POC POMI dengan \\
Dikirim 13 Desember 2020 & dosis kompos tricho jagung pada pertumbuhan kailan (Brassica oleraceae. L). \\
Diterima 16 Februari 2021 & Penelitian dilaksanakan di dalam Screen House Auto Agronom Fakultas Pertanian \\
Terbit 26 April 2021 & Universitas Islam Riau (UIR), Kota Pekanbaru. Penelitian ini adalah percobaan \\
& faktorial 4x4 dalam Rancangan Acak Lengkap (RAL) yang terdiri dari dua faktor, \\
& yaitu faktor P (POC POMI) yang terdiri dari empat taraf perlakuan dan faktor T \\
\hline Kata kunci: & (Kompos Tricho Jagung) juga dengan empat taraf perlakuan dengan tiga kali \\
Kailan & ulagan. Sehingga terdapat 48 plot, dalam satu plot terdapat 8 tanaman sedangkan \\
POC POMI & sampel diambil 4 tanaman secara acak pada masing - masing plot. Secara \\
Tricho jagung & keseluruhan jumlah tanaman kailan yang digunakan sebanyak 384 batang. Tinggi \\
Interaksi & tanaman (cm), jumlah daun (helai) dan volume akar (cm ${ }^{3}$ ) merupakan parameter \\
& utama dalam penelitian ini. Interaksi konsentrasi POC POMI serta dosis kompos \\
& tricho jagung menunjukkan pengaruh pada tinggi tanaman dengan perlakuan \\
& terbaik konsentrasi POC POMI 15 ml/polybag serta kompos tricho jagung dosis \\
\hline Keywords: & 150 g polybag. Perlakuan tunggal POC POMI berpengaruh nyata terhadap seluruh \\
POC POMI & parameter pengamatan dengan perlakuan terbaik konsentrasi POC POMI 15 \\
Corn tricho & ml/polybag. Sedangkan pemberian kompos tricho jagung secara tunggal juga \\
Interaction & pengaruh nyata terhadap seluruh parameter pengamatan. Perlakuan terbaik dengan \\
& dosis kompos tricho jagung 150 g / polybag. \\
\hline
\end{tabular}

\section{A B S T RA C T}

This study aimed to examine the impact of POC POMI concentration with a dose of corn tricho compost on the growth of kailan (Brassica oleraceae. L). The research was conducted in the Screen House Auto Agronomist, Faculty of Agriculture, Islamic University of Riau (UIR), Pekanbaru City. This study was a $4 \times 4$ factorial experiment in a completely randomized design (CRD) consisting of

Kutipan format APA: Narullova, W.

(2021).Aplikasi POC POMI dan Kompos Tricho Jagung terhadap Pertumbuhan Kailan (Brassica oleraceae. L). AgriHumanis: Journal of Agriculture and Human Resource Development Studies, 2(2), 109-118. two factors, namely factor P (POC POMI) which consisted of four treatment levels and factor $T$ (Tricho Corn Compost) also with four levels of treatment with three replications. So that there are 48 plots, in one plot there are 8 plants while the sample is taken at random 4 plants in each plot. Overall the number of kailan plants used was 384 stems. Plant height (cm), number of leaves (strands) and root volume (cm3) are the main parameters in this study. The interaction of POC POMI concentration and dose of corn tricho compost showed an effect on plant height with the best treatment being the concentration of POC POMI $15 \mathrm{ml} / \mathrm{polybag}$ and corn tricho compost at a dose of $150 \mathrm{~g} / \mathrm{polybag}$. The single treatment of POC POMI significantly affected all observation parameters with the best treatment being the concentration of POC POMI $15 \mathrm{ml}$ polybag. While giving corn tricho compost singly also has a significant effect on all observation parameters. The best treatment was with a dose of corn tricho compost $150 \mathrm{~g} /$ polybag.

\section{PENDAHULUAN}

Kailan (Brassica oleracea L.) merupakan jenis sayuran populer yang rasanya enak dan renyah serta mempunyai gizi tinggi. Kailan dijadikan sumber makanan yang banyak mengandung vitamin A dan $\mathrm{C}$ serta mineral $\mathrm{Ca}$ dan $\mathrm{Fe}$, sehingga bermanfaat bagi kesehatan. Kailan dipercaya sebagai tanaman 
yang sangat produktif bagi daerah tropis. Meskipun di Indonesia kailan tergolong jenis sayuran baru tetapi tanaman ini termasuk sayuran daun yang memiliki nilai ekonomi tinggi. Ditinjau dari segi aspek bisnis dan ekonomis, kailan layak dikembangkan karena umur panen relatif pendek yakni umur 35-45 hari setelah tanam (hst) dan hasilnya memberikan keuntungan yang memadai (Anonim, 2013).

Permintaan pasar komoditas tanaman kailan semakin meningkat seiring dengan peningkatan jumlah penduduk, tingkat pendidikan masyarakat, tingkat pendapatan dan kesukaan masyarakat terhadap kailan. Ditingkat ekspor, permintaan kailan cukup besar yakni 72 ton pertahun sementara Riau hanya mampu menyediakan 25 ton pertahun. Ada beberapa hambatan yang menyebabkan rendahnya produksi kailan diantaranya kurangnya penerapan panca usaha tani yakni penggunaan varietas unggul, pemupukan, pengairan, pengendalian hama dan penyakit, serta lahan yang tersedia (Wikipedia indonesia kailan, 2009).

Untuk meningkatkan produksi kalian, usaha yang dapat dilakukan antara lain dengan memperluas areal penanaman, penerapan teknik budidaya yang baik, serta menjaga kesuburan lahan pertanian supaya kesinambungan usaha pertanian tetap terlaksana. Pertanian berkesinambungan merupakan teknik budidaya pertanian yang menitikberatkan pada pelestarian hubungan timbal balik antara organisme dengan sekitarnya. Sistem pertanian berkesinambungan tidak menghendaki penggunaan produk berupa bahan kimia yang dapat merusak alam. Pertanian berkesinambungan identik dengan penggunaan pupuk organik yang berasal dari limbah-limbah pertanian, pupuk kandang, pupuk hijau, kotoran-kotoran manusia, serta kompos. Penerapan pertanian organik diharapkan keseimbangan antara organisme dengan lingkungan tetap terjaga (Djojosuwito, 2000).

Salah satu jenis pupuk organik yang diformulasi untuk tanaman semusim termasuk sayursayuran adalah Pupuk organik cair "POMI". Keunggulan dari pupuk organik cair POMI adalah dapat meningkatkan produksi tanaman, mengurangi resiko gugur bunga dan buah, dapat memperkuat jaringan pada akar dan batang, serta dapat berfungsi sebagai katalisator sehingga akar dapat lebih mudah menyerap unsur hara dari dalam tanah.

Selain itu penggunaan pupuk organik cair POMI memiliki keunggulan yang mana keseimbangan vitamin dan fitohormon yang terkandung di dalamnya selain berbasis mikrobia juga bekerja mengurai tanah pertanian kelebihan unsur NPK yang berasal dari pupuk kimia dan tidak terserap oleh tanaman. Ketika kita menaburkan pupuk kimia ke tanah pertanian diperkirakan hanya $\pm 20-25 \%$ unsur hara tersebut terserap tanaman, sisanya akan tetapdi dalam tanah yang berdampak makin padat/pekatnya kondisi tanah pertanian tersebut. Kondisi ini jika dibiarkan secara terus menerus diperkirakan dalam jangka 10-12 tahun mendatang lahan kita sudah tidak produktif lagi alias gersang, sehingga tidak bisa dipakai untuk menanam tanaman pangan. Dengan adanya mikrobia yang terkandung di dalam POMI, maka mikrobia tersebut akan masuk ke dalam tanah dan bekerja mengurai residu unsur NPK di dalam tanah sehingga akan naik ke atas dan dapat diserap tanaman.

Sumber bahan organik yang banyak tersedia di sekitar kita adalah sisa tanaman jagung yang merupakan sampah organik yang tidak digunakan dalam budidaya jagung. Pemanfaatan sisa tanaman jagung dapat dilakukan dengan cara pengomposan. Kompos tricho - jagung merupakan pupuk organik yang dihasilkan dari sisa tanaman jagung yang didekomposisi dengan Trichoderma sp.

Tricho-kompos limbah jagung mampu menjadi pupuk yang dapat menyediakan unsur hara dalam tanah karena proses pelapukannya lebih cepat. Selain kandungan unsur hara yang ada pada limbah jagung, kemampuan Trichoderma sp. Sebagai dekomposer juga memiliki kemampuan peran antagonis terhadap penyakit tular tanah, sehingga diharapkan dapat meningkatkan pertumbuhan dan produksi tanaman kailan. Pemberian Tricho-kompos limbah jagung pada tanah Inceptisol diharapkan menunjang perkembangan organisme tanah, sehingga sifat tanah semakin baik dan tersedianya unsur hara yang dapat dimanfaatkan oleh tanaman kailan. Dengan demikian penyerapan unsur hara dari tanah oleh akar tanaman kailan semakin baik, maka pertumbuhan tanaman kailan semakin baik

Penelitian ini bertujuan untuk mengetahui pengaruh interaksi POC POMI dan kompos tricho jagung, pengaruh tunggal berbagai dosis POC POMI, serta pengaruh tunggal berbagai dosis kompos tricho jagung pada pertumbuhan Kailan (Brassica oleraceae. L).

\section{METODE}

\subsection{Lokasi dan Rancangan Penelitian}

Penelitian kailan di dalam screen house auto agronom kebun percobaan Fakultas Pertanian Universitas Islam Riau, Kota Pekanbaru ini dilaksanakan selama kurang lebih 2 bulan. Penelitian ini menggunakan Percobaan Faktorial 4 x 4 dalam Rancangan Acak Lengkap (RAL) yang terdiri dari dua 
faktor, yaitu faktor P (POC POMI) yang terdiri dari 4 taraf perlakuan dan faktor T (kompos tricho jagung) juga dengan 4 taraf perlakuan, dengan tiga kali ulangan.

Faktor P (pupuk organik cair POMI) terdiri dari 4 taraf, yaitu :

$\mathrm{P0}=$ Tanpa pemberian POC POMI (kontrol)

$\mathrm{P} 1=$ Pemberian POC POMI konsentrasi $5 \mathrm{ml} /$ polybag

$\mathrm{P} 2=$ Pemberian POC POMI konsentrasi $10 \mathrm{ml} /$ polybag

$\mathrm{P} 3$ = Pemberian POC POMI konsentrasi $15 \mathrm{ml} /$ polybag

Faktor T (kompos Tricho-Jagung) terdiri dari 4 taraf, yaitu :

T0 = Tanpa pemberian Kompos Tricho-Jagung (kontrol)

$\mathrm{T} 1=$ Pemberian Kompos Tricho-Jagung dosis 50 g/polybag

$\mathrm{T} 2$ = Pemberian Kompos Tricho-Jagung dosis $100 \mathrm{~g} /$ polybag

$\mathrm{T} 3$ = Pemberian Kompos Tricho-Jagung dosis $150 \mathrm{~g} /$ polybag

Data hasil pengamatan yang diperoleh dari masing - masing perlakuan dianalisis secara statistik dengan sidik ragam (ANOVA). Apabila F hitung lebih besar dari F tabel, dilakukan uji lanjut Beda Nyata Jujur (BNJ) pada taraf 5\%.

\subsection{Pelaksanaan Penelitian}

\subsubsection{Persiapan Tempat Penelitian}

Areal yang digunakan untuk penelitian adalah areal di dalam screen house auto agronom yang telah bersih dari semua gulma. Media tanam yang merupakan tanah diisi dalam keadaan kering sebanyak $5 \mathrm{~kg}$. Tanah berasal dari sekitar kebun percobaan yang merupakan tanah hasil penelitian - penelitian sebelumnya. Media tanam berupa tanah tersebut diberi pupuk dasar berupa pupuk kandang dengan dosis $1 \mathrm{~kg} /$ polybag. Setelah itu polybag disusun dalam laboratorium auto agronom yang terdiri dari 4 baris dimana di dalam satu barisnya terdapat 48 satuan percobaan sesuai dengan perlakuan masing - masing.

\subsubsection{Persemaian (Persiapan Bibit)}

Sebelum dilaksanakan penanaman, terlebih dahulu dilakukan kegiatan persemaian benih agar diperoleh bibit yang baik dan seragam. Benih kailan direndam dalam air dingin selama 15 menit lalu dikeringkan kembali. Benih tersebut disemaikan pada satu wadah terai benih berukuran $50 \mathrm{~cm} \times 1 \mathrm{~m}$ dengan cara membenamkan benih pada kedalaman $1 \mathrm{~cm}$ dari permukaan tanah kemudian diletakkan wadah tersebut dibawah naungan. Selama 2 minggu di persemaian bibit dipelihara secara intensif terutama penyiraman dan pengawasan terhadap serangan hama atau penyakit. Bibit dirawat hingga siap ditanam ke lapangan setelah mempunyai daun sebanyak 3 helai.

\subsubsection{Pemasangan Label}

Untuk mempermudah dalam penyusunan denah penelitian, maka dilakukan pemasangan label pada saat seminggu sebelum tanam sesuai dengan perlakuan masing - masing. Tujuan pemasangan label untuk mempermudah dalam kegiatan pemberian perlakuan serta mempermudah dalam proses pengamatan dilapangan. Pemasangan label dilakukan berdasarkan denah penelitian.

\subsubsection{Pemberian Perlakuan}

Seminggu sebelum tanam bersamaan dengan pengisian polybag sesuai dengan perlakuan masingmasing, dilakukan pemberian kompos Tricho-jagung. Pemberian kompos Tricho-jagung dilakukan dengan cara mengaduk rata dengan tanah yang telah disiapkan sebelumnya dan dimasukkan kedalam polybag. Sementara itu pemberian pupuk organik cair POMI dilakukan dengan cara kocor pada lubang tanam 2 hari sebelum tanam dengan konsentrasi sesuai dengan perlakuan masing - masing. Kemudian pupuk organik cair POMI disemprotkan pada daun, batang dan akar tanaman sejak umur 15 hari setelah tanam sesuai dengan konsentrasi masing - masing perlakuan. Setelah itu pupuk organik cair POMI disemprotkan setiap 15 hari sekali dengan volume 1 liter/polybag yang sebagian disemprotkan ke daun dan sebagian lagi disiramkan ke pangkal batang.Penyemprotan dilakukan sore hari setelah jam 4 (saat hari cerah / tidak hujan). Hal ini dilakukan sampai dengan akhir penelitian.

\subsubsection{Penanaman}

Penanaman dilakukan pada waktu bibit tanaman kailan telah memiliki 3 helai daun atau berumur dua minggu. Bibit diambil dari tempat persemaian dengan menggunakan sungkit kayu. Untuk memudahkan pencabutan bibit terlebih dahulu disiram dengan air. Bibit tanaman kailan dipindahkan secara hati - hati kedalam polybag yang sebelumya telah diisi media tanah dan campuran kompos tricho jagung. Bibit tanaman kailan yang akan dipindahkan sebelumya telah diseleksi agar diperoleh bibit yang baik, sehat dan seragam. 


\subsubsection{Pemeliharaan}

Ada dua kegiatan yang dilakukan dalam pemeliharaan ini, yaitu penyiraman dan penyiangan. Penyiraman dilakukan secara otomatis melalui selang yang berada dalam screen house auto agronom. Volume air yang diterima tanaman sebanyak $33 \mathrm{ml} / 30$ menit/polybag. Apabila suhu didalam screen house auto agronom diatas $30 \mathrm{oC}$, maka secara otomatis akan menghidupkan fogging dan akan turun embun berupa butiran - butiran air yang berfungsi untuk mendinginkan ruangan. Tujuan dari penyiraman agar terpenuhinya kebutuhan air pada tanaman sehingga tanaman dapat tumbuh normal sesuai dengan yang diharapkan. Sedangkan penyiangan dilakukan apabila disekitar lahan dan dalam polybag terdapat gulma yang mengganggu. Penyiangan dilakukan secara manual yakni dengan cara mencabut gulma tersebut sampai ke akar.

\subsubsection{Panen}

Pemanenan tanaman kailan dapat dilakukan setelah tanaman memenuhi kriteria panen yaitu bentuk helaian daun sudah maksimal atau berumur 40 hari. Pemanenan dilakukan dengan cara mencabut seluruh bagian tanaman kailan sampai ke akarnya, harus hati - hati jangan sampai daunnya robek atau tangkainya patah. Pemanenan sebaiknya pagi hari atau keadaan tanah masih lembab sehingga memudahkan dalam pencabutan.

\subsection{Parameter Pengamatan}

Ada tiga parameter pengamatan yang diamati dalam penelitian ini, diantaranya yaitu :

\subsubsection{Tinggi tanaman $(\mathrm{cm})$}

Pada akhir penelitian yakni pada umur 40 hari dilakukan pengukuran tinggi tanaman dengan menggunakan penggaris dimulai dari pangkal tanaman sampai ke helai daun yang tertinggi.

\subsubsection{Jumlah daun (helai)}

Pada akhir penelitian juga dihitung pengamatan jumlah helai daun secara keseluruhan pada tanaman sampel. Daun yang terbentuk atau membuka sempurna pada saat pengamatan merupakan daun yang bisa dihitung dalam pengamatan.

\subsubsection{Volume akar $\left(\mathrm{cm}^{3}\right)$}

Sebelum dihitung volume akarnya, terlebih dahulu akar kailan dipotong bagian leher akar (batas antara batang dan akar). Akar yang telah dipotong dari batang tanaman dibersihkan dari kotoran yang melekat lalu dimasukkan ke dalam breaker glass yang telah berisi air. Penambahan volume air sewaktu dimasukan kedalam breaker glass merupakan volume akar.

\section{HASIL DAN PEMBAHASAN}

\subsection{Tinggi Tanaman $(\mathrm{cm})$}

Secara interaksi data pengamatan menunjukkan bahwa pemberian POC POMI dan kompos tricho jagung memberikan pengaruh pada parameter tinggi tanaman kailan. Begitu juga pengaruh utama pemberian POC POMI dan kompos tricho jagung nyata terhadap parameter tinggi tanaman Kailan. Rerata hasil pengamatan tinggi tanaman menurut hasil Uji lanjut BNJ pada taraf 5\% dapat dilihat pada tabel 1.

Tabel 1. Rerata tinggi tanaman dengan pemberian POC POMI dan kompos tricho jagung

\begin{tabular}{|c|c|c|c|c|c|}
\hline \multirow{2}{*}{$\begin{array}{l}\text { POC POMI } \\
\text { (ml / } 1 \text { air })\end{array}$} & \multicolumn{4}{|c|}{ Kompos Tricho Jagung (g/polybag) } & \multirow[t]{2}{*}{ Rerata } \\
\hline & T0 (kontrol) & $\mathrm{T} 1(50)$ & $\mathrm{T} 2(100)$ & $\mathrm{T} 3(150)$ & \\
\hline P0 (kontrol) & $23,67 \mathrm{~h}$ & $24,33 \mathrm{gh}$ & $23,67 \mathrm{~h}$ & $23,83 \mathrm{~h}$ & $23,88 \mathrm{~d}$ \\
\hline $\mathrm{P} 1(5,00)$ & 26,17 efg & 26,83 ef & 26,83 ef & $25,50 \mathrm{de}$ & $26,33 \mathrm{c}$ \\
\hline P2 $(10,00)$ & 26,17 efg & $27,83 \mathrm{e}$ & 27,00 ef & $30,83 \mathrm{~cd}$ & $27,96 \mathrm{~b}$ \\
\hline P3 $(15,00)$ & $32,00 \mathrm{~cd}$ & $33,67 \mathrm{c}$ & $36,33 \mathrm{~b}$ & $40,33 \quad \mathrm{a}$ & 35,58 a \\
\hline Rerata & $27,00 \quad \mathrm{c}$ & $28,17 \mathrm{~b}$ & $28,46 \mathrm{~b}$ & $\begin{array}{ll}30,13 & \mathrm{a}\end{array}$ & \\
\hline $\mathrm{KK}=2,58 \%$ & & $\mathrm{JP} \& \mathrm{~T}=$ & & $\mathrm{BNJ} \mathrm{PT}=$ & \\
\hline
\end{tabular}

Angka - angka pada baris dan kolom yang diikuti oleh huruf kecil yang sama tidak berbeda nyata menurut Uji lanjut BNJ pada taraf $5 \%$.

Maksimalnya tinggi tanaman pada perlakuan P3T3 (pupuk organik cair POMI 15ml / polybag dan kompos tricho jagung $150 \mathrm{~g} /$ polybag) disebabkan karena kombinasi jumlah konsentrasi pupuk organik cair POMI dan dosis kompos tricho jagung mampu memenuhi kebutuhan unsur hara $\mathrm{P}, \mathrm{K}$ dan Mg tanaman kailan dengan baik dan seimbang sehingga fotosintesis dan penyebaran asimilat hasil fotosintesis dari akar ke daun dan batang tanaman berlangsung dengan baik. Disamping itu, kondisi agregat, drainase, aerase, kemasaman dan bahan organik tanah yang baik, pemberian pupuk organik cair 
pomi dan kompos tricho jagung dengan konsentrasi dan dosis tinggi menyebabkan perakaran tanaman tumbuh dan berkembang dengan baik sehingga penyerapan hara berlangsung dengan baik pula. Fotosintesis dan penyebaran asimilat hasil foosintesis akibat ketersediaan hara dan penyerapan hara yang baik menyebabkan proses pertambahan tinggi tanaman lebih cepat berlangsung. Sutanto (2004) menyatakan bahwa dengan penggunaan bahan organik yang pengaplikasiannya selama 7-15 hari sebelum tanam dapat menghasilkan nitrogen yang segera tersedia sehingga mempercepat pertumbuhan tanaman.

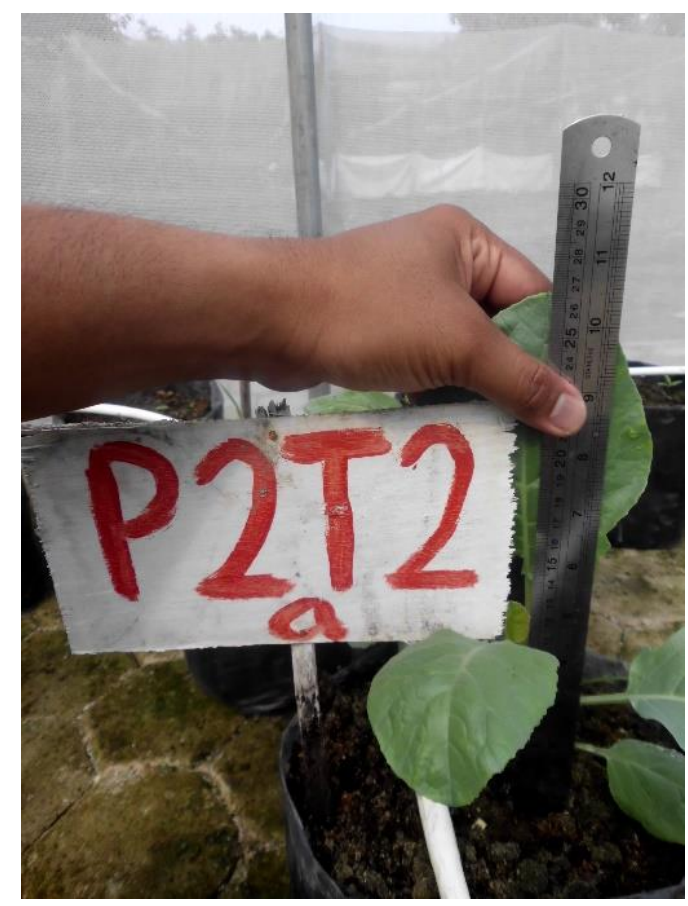

Gambar 1. Pengamatan tinggi tanaman pada saat panen

Pengaruh tunggal pemberian POC POMI nyata terhadap parameter tinggi tanaman kailan. Perlakuan terbaik terdapat pada P3 (pupuk organik cair POMI $15 \mathrm{ml} /$ polybag) dengan tinggi tanaman $35,58 \mathrm{~cm}$. Perlakuan P3 ini berbeda nyata dengan perlakuan lainnya, yaitu P0, P1 dan P2. Hal ini disebabkan kadar pemupukan organik yang teratur pada akhirnya dapat meningkatkan pengaruh terhadap tanaman (Yulianti, 2009).

Kemampuan pupuk organik walaupun kuantitas unsur haranya rendah tetapi mampu memberikan pengaruh besar pada tanah yang bisa bermanfaat untuk meningkatkan produktivitas lahan sehingga pertumbuhan dan perkembangan tanaman dapat meningkat secara optimal (Hasibuan, 2004).

Dosis pemberian pupuk juga menentukan pengaruh terhadap tanaman. Semakin tinggi dosis pemberian hingga mencapai maksimum maka pertumbuhan dan perkembangan tanaman akan maksimal. Sedangkan pemberian lebih rendah akan menurunkan pengaruh terhadap tanaman tersebut secara nyata (Lingga dan Marsono, 2007).

Sementara itu pengaruh utama perlakuan kompos tricho jagung nyata terhadap tinggi tanaman kailan. Dari data diatas dapat disimpulkan bahwa secara statistik perlakuan T3 merupakan perlakuan terbaik. Berbedanya perlakuan T3 dibandingkan dengan yang lainnya dikarenakan terpenuhinya unsur hara nitrogen, fosfor dan kalium yang terkandung dalam kompos tricho jagung dimana dengan dosis yang cukup dan pas dominan untuk menghasilkan tinggi tanaman. Yahya (2002) mengemukakan bahwa pertumbuhan dan produktivitas tanaman sayuran sangat tergantung pada unsur hara yang tersedia di dalam tanah.

\subsection{Jumlah Daun (helai)}

Hasil pengamatan jumlah daun dengan pemberian POC POMI dan kompos tricho jagung setelah dilakukan analisis sidik ragam terlihat bahwa interaksi perlakuan POC POMI dan kompos tricho jagung tidak berpengaruh nyata terhadap jumlah daun tanaman kailan. Akan tetapi, pengaruh utama perlakuan POC POMI dan kompos tricho jagung nyata terhadap jumlah daun tanaman kailan. Rerata hasil pengamatan jumlah daun menurut hasil Uji lanjut BNJ pada taraf 5\% dapat dilihat pada tabel 2. 
Tabel 2. Rerata jumlah daun dengan pemberian POC POMI dan Kompos Tricho - jagung

\begin{tabular}{cccccc}
\hline \multirow{2}{*}{$\begin{array}{c}\text { POC POMI } \\
\text { (m1 / 1 air) }\end{array}$} & \multicolumn{3}{c}{ Kompos Tricho Jagung (g /polybag) } & Rerata \\
\cline { 2 - 5 } & T0 & T1 (50) & T2 (100) & T3 (150) & \\
\hline P0 (kontrol) & 6,83 & 7,00 & 7,00 & 7,17 & $7,00 \mathrm{~d}$ \\
P1 (5) & 7,33 & 7,50 & 7,83 & 8,00 & $7,67 \mathrm{c}$ \\
P2 (10) & 8,17 & 8,67 & 8,67 & 9,17 & $8,67 \mathrm{~b}$ \\
P3 (15) & 10,00 & 10,33 & 10,83 & 11,83 & $10,75 \mathrm{a}$ \\
\hline Rerata & $8,08 \mathrm{c}$ & $8,38 \mathrm{bc}$ & $8,58 \mathrm{ab}$ & $9,04 \mathrm{a}$ & \\
\hline
\end{tabular}

$\mathrm{KK}=5,80 \% \quad$ BNJ P \& T $=0,49$

Angka - angka pada baris dan kolom yang diikuti oleh huruf kecil yang sama tidak berbeda nyata menurut Uji lanjut BNJ pada taraf $5 \%$.

Maksimalnya jumlah daun tanaman kailan dengan pemberian POC POMI $15 \mathrm{ml} /$ polybag dikarenakan pengaruh hormon auksin, sitokinin dan giberelin yang terkandung didalam POC POMI yang mampu menjadi stimulus pertumbuhan dan perkembangan sel dalam daun sehingga jumlah daun meningkat. Kandungan hormon tanaman pada POC POMI mampu mempercepat pertumbuhan batang, daun, bunga, buah dan akar tanaman (Anonim, 2014).

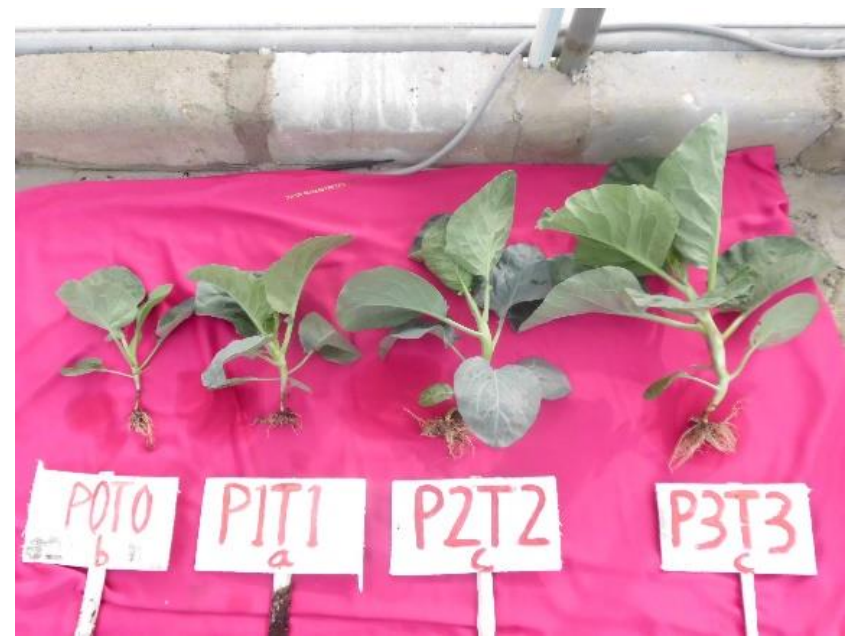

Gambar 2. Hasil pengamatan jumlah daun tanaman kailan setelah panen

Untuk meningkatkan ketersediaan unsur hara dan senyawa lainnya seperti hormon pertumbuhan pupuk organik dan pupuk hayati memiliki potensi besar dalam mewujudkan hal tersebut (Setyorini, dkk, 2006). Akan tetapi pengaruh yang dihasilkan tergantung pada dosis pemberian pemupukan. Peningkatan dosis pemberian pupuk organik dan pupuk hayati seperti POC POMI akan memberikan hasil lebih baik daripada pemberian dengan dosis yang lebih rendah. Ini dibuktikan dengan perlakuan P3 yang diberikan POC POMI sebanyak $15 \mathrm{ml} /$ polybag, memiliki jumlah daun yang lebih banyak dibandingkan dengan perlakuan P0 tanpa diberi POC POMI.

Ketersediaan unsur hara $\mathrm{P}$ dan $\mathrm{K}$ yang baik dan seimbang melalui pemberian POC POMI memberi pengaruh terhadap penambahan jumlah daun tanaman kailan. Menurut Lingga dan Marsono (2007), ketersediaan fosfor dan kalium yang berfungsi sebagai pembentuk senyawa protein, karbohidrat dan asam - asam amino serta mengaktifkan enzim - enzim tertentu dalam tubuh tanaman. Unsur fosfor dan kalium juga berperan dalam peningkatan pertumbuhan dan perkembangan jaringan meristem serta jaringan pembuluh secara maksimal karena karbohidrat yang dihasilkan akan disimpan dan ditumpuk pada jaringan meristem dan jaringan pembuluh sebagai sumber energi cadangan. Penumpukan ini menyebabkan pembengkakan jaringan meristem dan jaringan pembuluh karena jumlah karbohidrat yang ditimbun semakin lama akan semakin banyak (Hastuti, 2000).

Pengaruh utama pemberian kompos tricho jagung nyata terhadap jumlah daun tanaman kailan. Dari data diatas dapat disimpulkan bahwa secara statistik perlakuan T3 (kompos tricho jagung $150 \mathrm{~g} /$ polybag) merupakan perlakuan terbaik dengan jumlah daun 9,04 helai. Banyaknya jumlah daun pada 
perlakuan T3 menunjukkan peranan penting dari kompos tricho jagung karena kompos ini mengandung unsur $\mathrm{N}(1,05 \%), \mathrm{P} 2 \mathrm{O} 5$ (1,01\%), $\mathrm{K} 2 \mathrm{O}$ (0,18\%), $\mathrm{CaO}(1,98 \%), \mathrm{MgO}(0,53 \%)$, C-organik (10,5\%) dan $\mathrm{C} / \mathrm{N}$ ratio 9,97 (Surtinah, 2013). Aplikasi kompos juga mampu melonggarkan susunan tanah sehingga udara mudah menembus kedalam, dengan kata lain dapat memperbaiki aerase tanah dan meningkatkan daya serap tanah terhadap air sehingga ketersediaan air yang dibutuhkan tanaman tercukupi serta mendorong kehidupan dan perkembangan jasad renik tanah yang berguna untuk mengubah zat -zat makanan di dalam tanah (Surtinah, 2013).

\subsection{Volume Akar $\left(\mathrm{cm}^{3}\right)$}

Dari hasil pengamatan terhadap parameter volume akar setelah dilakukan analisis sidik ragam menunjukkan bahwa secara interaksi perlakuan POC POMI dan kompos tricho jagung tidak memberikan pengaruh terhadap volume akar tanaman kailan. Akan tetapi pengaruh utama perlakuan POC POMI dan kompos tricho jagung nyata terhadap volume akar tanaman kailan. Rerata hasil pengamatan volume akar menurut hasil Uji lanjut BNJ pada taraf 5\% dapat dilihat pada tabel 3.

Tabel 3. Rerata volume akar dengan pemberian POC POMI dan kompos tricho - jagung

\begin{tabular}{|c|c|c|c|c|c|}
\hline \multirow{2}{*}{$\begin{array}{l}\text { POC POMI } \\
\text { (ml / l air) }\end{array}$} & \multicolumn{4}{|c|}{ Kompos Tricho Jagung (g/polybag) } & \multirow[t]{2}{*}{ Rerata } \\
\hline & $\begin{array}{c}\text { T0 } \\
\text { (kontrol) }\end{array}$ & T1 (50) & $\mathrm{T} 2(100)$ & T3 (150) & \\
\hline P0 (kontrol) & 1,10 & 1,27 & 1,33 & 1,33 & $1,26 \mathrm{~b}$ \\
\hline P1 (5) & 1,27 & 1,59 & 1,53 & 1,46 & $1,46 \mathrm{~b}$ \\
\hline P2 (10) & 1,30 & 1,45 & 1,59 & 1,80 & $1,53 \mathrm{~b}$ \\
\hline P3 (15) & 2,00 & 2,29 & 2,42 & 2,79 & $2,38 \mathrm{a}$ \\
\hline Rerata & $1,42 \mathrm{~b}$ & $1,65 \mathrm{ab}$ & $1,72 \mathrm{a}$ & $1,85 \mathrm{a}$ & \\
\hline $\mathrm{KK}=17,44 \%$ & \multicolumn{5}{|c|}{ BNJ P \& T = 0,29 } \\
\hline
\end{tabular}

Tingginya rerata volume akar pada perlakuan P3 disebabkan oleh pemberian POC POMI melalui daun dapat menambah kebutuhan hara $\mathrm{N}$ dan $\mathrm{K}$ untuk berlangsungnya proses metabolisme tanaman. Pemupukan melalui daun lebih cepat penyerapan haranya dibandingkan lewat akar (Nasaruddin 2010).

Pupuk daun dapat memberikan persediaan hara pada tanaman, walaupun hara yang diberikan relatif sedikit. Fase pertumbuhan vegetatif tanaman sangat erat kaitannya dengan pemberian pupuk. Simalango (2009) mengatakan bahwa pemupukan secara organik mampu berperan memobilisasi atau menjembatani hara yang sudah ada di tanah sehingga mampu membentuk partikel ion yang mudah diserap oleh akar tanaman.

Pemberian kompos tricho jagung memberikan pengaruh pada volume akar, dimana semua dosis perlakuan (T3, T2, T1) tidak berbeda tetapi sangat berbeda dengan kontrol (T0). Ini menunjukkan pemberian kompos tricho jagung memiliki pengaruh yang sama dalam pertumbuhan volume akar dibandingkan dengan kontrol. Pada kontrol pertumbuhan volume akar lebih kecil dibandingkan dengan yang lain diakibatkan pada tanah yang tidak mengandung bahan organik menyebabkan menurunkan stabilitas struktur tanah sehingga pertumbuhan volume akar mengarah untuk memperoleh bahan organik di bagian dalam. Berbeda dengan medium yang diberi kompos organik pertumbuhan akar lebih banyak yang dapat merangsang peningkatan volume akar tanaman kailan (Herlina, 2010).

Kailan yang diberi kompos tricho jagung pertumbuhan akarnya lebih banyak, dikarenakan adanya bahan organik menyebabkan partikel tanah menjadi remah dan meningkatkan stabilitas tanah, menyediakan makanan dan tempat hidup organisme tanah. Hal ini sejalan dengan penelitian Suwahyono (2003) yang mengatakan bahwa sawi hijau kompos trichoderma sistem perakarannya lebih banyak dibandingkan tanpa pemberian kompos trichoderma aktif. Pemberian trichoderma dalam kompos tricho jagung yang aktif bisa merangsang pembentukan akar lateral. Dilaporkan juga bahwasanya trichoderma mengeluarkan zat aktif semacam hormon auksin yang dapat merangsang pembentukan akar lateral (Suwahyono, 2004).

Pertumbuhan tanaman termasuk akarnya merupakan hasil pembelahan sel-sel meristem dan pembentangan sel hasil pembelahan. Unsur hara dan air berperan dalam mempengaruhi pertumbuhan akar, seperti dikemukan oleh Sutanto (2004) bahwa akar merupakan pintu masuk hara dan air dan zat terlarut di dalamnya ke tempat dibutuhkan tanaman, selanjutnya fotosintesis akan dimanfaatkan untuk pertumbuhan tanaman termasuk pertumbuhan akar primer dan lateral. 


\section{KESIMPULAN DAN SARAN}

\subsection{Kesimpulan}

Dari hasil penelitian yang telah dilaksanakan, maka didapat kesimpulan bahwa Interaksi pemberian POC POMI dan kompos tricho jagung berpengaruh terhadap tinggi tanaman. Perlakuan terbaik adalah dengan konsentrasi POC POMI $15 \mathrm{ml} /$ polybag dan kompos tricho jagung dosis $150 \mathrm{~g} /$ polybag. Kemudian pengaruh tunggal pemberian POC POMI nyata terhadap seluruh parameter pengamatan. Perlakuan terbaik yaitu dengan pemberian pupuk organik cair POMI $15 \mathrm{ml} /$ polybag. Sedangkan untuk pengaruh tunggal pemberian kompos tricho jagung nyata terhadap seluruh parameter pengamatan. Perlakuan terbaik yaitu dengan pemberian kompos tricho jagung $150 \mathrm{~g} /$ polybag.

\subsection{Saran}

Berdasarkan penelitian yang telah dilakukan, untuk mendapatkan pertumbuhan kailan yang paling baik perlu disarankan menggunakan POC POMI konsentrasi $15 \mathrm{ml} /$ polybag dan kompos tricho jagung dosis $150 \mathrm{~g} /$ polybag. Selain itu, perlu adanya penelitian lanjutan dalam hal pemberian POC POMI dan kompos tricho jagung disebabkan kedua pupuk organik ini terbilang masih baru di dalam dunia pertanian khususnya di Provinsi Riau.

\section{DAFTAR PUSTAKA}

Anonim. (2014). http://www.kaskus.co.id/thread/53ccca67bccb1753378b4691/pupuk-bio-organikpomi-dan-decomposser-beka

Anonim. (2013). Pedoman Budidaya Secara Hidroponik. Bandung: Nuansa Aulia.

Arifa, A. (2007). Pemanfaatan Trichoderma SP dan Dreg Pada Medium Gambut Untuk Pertumbuhan Kelapa Sawit di Pembibitan Utama. Skripsi Fakultas Pertanian Universitas Riau. Pekanbaru.

Darmawan. (2009). Kailan dan Budidayanya. Jakarta: Penebar Swadaya.

Djojosuwito, S. (2000). Pertanian Organik dan Multiguna. Yogyakarta: Kanisisus.

Hasibuan, B. E. (2004). Pupuk dan Pemupukan. Fakultas Pertanian Universitas Sumatera Utara. Medan.

Hastuti, E. D., Prihastanti, E. \& Hastuti, R. B. (2000). Fisiologi Tumbuhan II. Universitas Diponegoro Press. Malang.

Herlina, L. \& Dewi, P. (2010). Penggunaan Kompos Aktif Trichoderma Harzianum Dalam Meningkatkan Pertumbuhan Tanaman Cabai. Skripsi Fakultas Matematika dan Ilmu Pengetahuan Alam. Universitas Negeri Semarang. Semarang. http://situsrumahkita.blogspot.com/2010_02_01_archive.html.

Lingga, P \& Marsono. (2007). Petunjuk Penggunaan Pupuk. Jakarta: Edisi Revisi Penebar Swadaya.

Narullova, W. (2009). Pengaruh Penggunaan Berbagai Macam Pupuk Organik dan Dosis Rootone - F Terhadap Pertumbuhan Setek Kamboja Jepang (Adenium, spp). Skripsi Fakultas Pertanian Universitas Islam Riau. Pekanbaru.

Nasaruddin. (2010). Nutrisi tanaman Jilid 1. Fakultas Pertanian Universitas Hasanuddin, Makasar. Tidak Dipublikasikan.

Puspita. (2006). Aplikasi Beberapa Dosis Tricho Kompos Terhadap Pertumbuhan dan Produksi Tanaman Sawi (Brassica juncea L.). Skripsi Fakultas Pertanian Universitas Riau. Pekanbaru.

Sagwansupyakorn, C. (1992). Brassica oleraceaL. cv. group Chinese Kale. Di dalam: L.J.G. van der Maesen, S. Somaatmdja, editor. Plant Resouces of South- East Asia (Prosea) No 1 Pulses. Bogor (ID): Prosea Foundation. 115-117.

Setyorini, D. R., Suraswatidan, E. K. \& Anwar. (2006). Pupuk Organik dan Pupuk Hayati. Jurnal Penelitian Fakultas Pertanian Universitas Padjadjaran Kampus Jatinangor. Bandung.

Simalango, E. (2009). Keuntungan Menggunakan Pupuk Organik. http://eriantosimalango.wordpress.com/2009/05/14/keuntungan-menggunakan-pupukorganik/[15/10/2011/ (diakses pada tanggal 5 September 2020).

Surtinah. (2013). Pengujian Kandungan Unsur Hara Dalam Kompos yang Berasal dari Serasah Tanaman Jagung Manis (Zea mays saccharata). Jurnal ilmiah Pertanian Universitas Gajah Mada. 11 (1) : 16 25.

Sutanto, R. (2004). Penerapan Pertanian Organik. Pemasyarakatan dan Pengembangannya. Yogyakarta: Kanisius.

Suwahyono, U \& Wahyudi, P. (2004). Penggunaan biofungisida pada usaha perkebunan. Dalam internet : http://www.iptek.net.id/ind/terapan/terapan_idx.php?doc=artikel_12 (diakses pada tanggal 20 Oktober 2020).

Suwahyono. (2003). Trichoderma harzianum indigeneous untuk pengendalian hayati. Studi Dasar Menuju Komersialissi dalam Panduan Seminar Biologi. Yogyakarta: Fakultas Biologi UGM. 
(www.id.wikipedia.org/wiki/kailan 2009).wikipediaindonesia kalian.

Yahya, S. (2002). Budidaya Sayur - sayuran. Bogor: Fakultas Pertanian IPB.

Yulianti, N. (2009). Cara Menghasilkan Pupuk Organik. Yogyakarta: Lily Publisher. 
[Halaman ini sengaja dikosongkan] 